\title{
METODOLOGISKA REFLEKTIONER
}

\section{När man vill veta hur det går för klienterna}

\author{
Att använda sociala akter i utvärdering av \\ socialbidragsarbetets effekter.
}

\section{PIA MILTON}

\begin{abstract}
Bristen på tillräckligt stora datamaterial av god kvalitet anges ofta som ett hinder att genomföra effektutvärderingar inom socialt arbete. I det dagliga arbetet dokumenterar socialarbetarna emellertid en mängd uppgifter om sina klienter i de sociala akterna. I den här artikeln diskuterar jag möjligheter och begränsningar i att använda sociala akter som informationskälla i utvärdering av socialbidragsarbetets effekter utifrän erfarenheterna frän en nyligen genomförd studie.
\end{abstract}

Inom socialtjänstens individ- och familjeomsorg är arbetet med ekonomiskt stöd till enskilda och familjer en av de mest betydelsefulla insatserna såväl till omfattning som kostnader. Det är också en socialpolitiskt brännbar fråga. Förutom att bidragstagarna ska tillförsäkras en skälig levnadsnivå anger socialtjänstlagen att bidragsarbetet ska utformas så att det stödjer indi-

Pial Milton är sociolog och forskningsledare vid Socialstyrelsen videns möjlighet att försörja sig själv, helst genom arbete på den öppna arbetsmarknaden. Behovet av - och kravet på - att följa upp och utvärdera det sociala arbetets metoder och särskilt effekterna för klienternas del har därför blivit alltmer uttalat de senaste åren. Fortfarande är emellertid sådana studier av olika skäl sällsynta både i vårt land och internationellt (Cheetham 1992, Palfrey et al. 1994). Förutom etiska hänsyn och metodmässiga problem kan bristen på tillräckligt stora datamaterial av god 
kvalitet försvåra möjligheten att genomföra effektutvärderingar. I den här artikeln diskuterar jag möjligheter och begränsningar $i$ att använda sociala akter som informationskälla i utvärdering av socialbidragsarbetets effekter. Erfarenheterna från en nyligen genomförd studie används som empiriskt exempel. Eftersom jag främst fokuserar på metodologiska frågeställningar och särskilt validitetsproblematiken i effektutvärderingar redovisas den empiriska studiens resultat endast kortfattat. En fullständig presentation av studiens design, metod och resultat har tidigare redovisats i Milton \& Bergström (1998). Jag presenterar först några centrala frågeställningar och metoder vid effektutvärdering av socialbidragsarbetet, diskuterar för- och nackdelar med sociala akter som datakällor, sammanfattar kort den empiriska studiens uppläggning och resultat och beskriver därefter hur vi gick tillväga vid insamling och analys av uppgifter i de sociala akterna i syfte att så långt möjligt kontrollera studiens reliabilitet och validitet.

\section{Några centrala frågor och metoder i effektutvärdering}

En central fråga i utvärdering av socialbidragsarbetet är vilka arbetsmetoder som bättre än andra kan hjälpa bidragstagarna att bli självförsörjande. Det finns olika sätt att mäta effekten av sociala insatser för klienternas del, samtliga med sina för- och nackdelar. Allmänt sett skiljer man på experimentell och icke-experimentell utvärdering. Den klassiska utvärderingsdesignen med syftet att studera effekterna av en eller flera insatser har inneburit experiment, som omfattar mätning av relevanta variabler för åtminstone två jämförbara grupper, där fallen är slumpmässigt fördelade på en experimentgrupp som erhåller en insats eller deltar i ett program och en kontrollgrupp som inte gör det. Individerna i de två grupperna följs under en viss tid för att man ska kunna uppskatta insatsernas relativa effekter och besvara frågor om vilka insatser som fungerar bättre än andra, för vilka individer och för hur lång tid(Campbell \& Stanley 1966, Rossi \& Freeman 1993). Metoden kan av flera skäl vara problematisk eller omöjlig att genomföra vid studier av den sociala praktiken, exempelvis kan socialarbetarna ifrågasätta att bara vissa klienter erbjuds insatsen, antalet klienter kanske inte är tillräckligt många för att man skall få tillräckligt stora grupper och faktorer i omvärlden eller i det sociala programmet/insatsen kan förändras (Weiss 1972, Boruch 1997). Experiment är också sårbara för Hawthorneeffekten, dvs. resultaten påverkas av den uppmärksamhet som deltagarna i experimentgruppen får och effekterna kan inte knytas till själva insatsen.

I icke-experimentella utvärderingar (kvasi-experiment) konstrueras kontrollgruppen för att vara så lik experimentgruppen som möjligt med hänsyn till relevanta variabler. I dessa utvärderingar sker alltså ingen slumpmässig fördelning av individerna till experiment- och kontrollgrupp. Andra faktorer avgör fördelningen, exempelvis lagstiftning, lokala riktlinjer och regler eller självselektion - dvs. att individerna själva väljer grupp. Statistiska metoder används ofta för att korrigera för skillnader som ändå kan finnas mellan de båda grupperna. Svårigheten är att konstruera en adekvat kontrollgrupp och därigenom säker- 
ställa jämförbarheten. Goda data är naturligtvis grunden för alla utvärderingar, även de icke-experimentella. Det är viktigt att det finns tidsseriedata för individuella bakgrundsfaktorer och för utfallsvariablerna både för experimentgruppen och kontrollgruppen så att man kan få en bild av förloppet i båda grupperna (Boruch 1997). Undersökningsperioden bör vara relativt lång för att effekterna av insatsen ska kunna avgöras; över tid kan effekterna variera, korttidseffekter kan t.ex. vara annorlunda än långtidseffekter. Eftersom effekten alltid bedöms i relation till en jämförelsegrupp är det också viktigt att omvärldsfaktorer, exempelvis arbets- och utbildningsmarknad är desamma för grupperna. I gynnsamma fall har man både före- och efterdata för båda grupperna. I utvärderingssammanhang förekommer också före-efter-studier utan kontrollgrupp, i vilka ett antal individer studeras före, under och efter en insats. Problemet är att man inte kan kontrollera för om förändringar orsakas av insatsen eller av andra faktorer i omvärlden och resultaten går därför inte att med säkerhet knyta till insatsen.

\section{För-och nackdelar med att använda uppgifter från sociala akter}

Många utvärderingar bygger på intervjuer och enkäter till socialtjänstens ledning, personal, klienter och anhöriga. Data kan också inhämtas genom observationer, register och sociala akter. I akterna registrerar socialarbetarna en mängd uppgifter främst om familjens sammansättning, inkomster och utgifter, om anledningen till att man söker ekonomiskt stöd samt om beslut, ändamål och den tidsperiod bidraget avser. Dokumentation i ärenden som rör enskilda individer regleras i socialtjänstlagen, förvaltningslagen och sekretesslagen, förutom i råd och anvisningar som utformats både centralt och lokalt. Informationen används främst i det dagliga arbetet, med syfte att underlätta administrationen och garantera rättsäkerhet (Bernler \& Johnsson 1993). Sedan bara några år tillbaka sker dokumentationen med hjälp av datorstöd i de flesta kommuner (Edholm \& Jacobsson 1999). I de flesta dataprogram som används i socialbidragsarbetet dokumenteras uppgifter om bidragstagarensfamiljeförhållanden, inkomster och utgifter, orsak till bidragsansökan samt beslutsmotivering, ändamål och tidsperiod bidraget avser.

Trots att denna information existerar och är tillgänglig med hänsyn till regler om dataskydd och integritet - har forskare sällan använt den, främst med hänvisning till dess bristande reliabilitet, dvs. att den inte är tillförlitlig, och bristande validitet, dvs. att data sällan är relevanta för utvärderingsstudiernas syften och frågeställningar och därför inte kan bidra till möjligheterna till generaliseringar utifrån studierna(Kagle 1983). Uppgifternas kvalitet har ifrågasatts bl a därför att de inte samlats in med syfte att utvärderas och forskaren blir hänvisad till socialsekreterarens subjektiva bedömningar av dels vilken information som skall dokumenteras, dels till socialsekreterarens tolkningar av de uppgifter som erhålls. Information som är värdefull för forskningen, om klienternas bakgrund och de sociala insatsernas innehåll och effekt, saknas dessutom ofta (Bergmark 1991, Buhr \& Ludwig \& 
Priester 1990). Det kan därför ofta vara svårt att avgöra vilket syfte, karaktär och utfall insatserna har (Mclvor 1989, Fuller \& Petch 1989). De reliabilitets- och validitetsproblem som föreligger vid analyser av sociala akter kan i bästa fall undvikas i studier baserade på primärdata, vilka därför många gånger är att föredra.

I vissa utvärderingsstudier, särskilt av retrospektiv art när man vill studera ett tidigare program eller metod, kan det emellertid vara nödvändigt att använda information som dokumenterats i akterna (Ben Shahar et al. 1995; Epstein et al. 1997). I jämförelse med studier baserade på primärdata kan användning av aktdata i vissa fall också vara ett snabbare sätt att samla information, mindre kostsam, medför färre etiska problem och vara mindre störande för socialbyråernasarbetsrutiner(Cheetham et al. 1992). Andra fördelar är tillgången till longitudinella retrospektiva data som inte påverkats av forskarens intresse för dem. Genom att uppmärksamma de problem och begränsningar som informationen i akterna omfattar och vidta åtgärder som är ägnade att reducera materialets begränsningar kan det vara möjligt att skapa valida och reliabla variabler och kvalitativt goda databaser för effektstudier.

\section{Reliabilitets- och validitetsproblematiken. Några åtgärder för att reducera problemen}

Felaktiga stickprov, tolkningsproblem och intervjuareffekter kan hota undersökningsresultatens reliabilitet, dvs. tillförlitlighet. Låg reliabilitet indikerar mätfel och begrän- sar också validiteten. Problemen kan minskas genom slumpmässiga urval och klara definitioner av de begrepp man använder. I effektutvärderingar har främst validitetsproblematiken uppmärksammats. De kända amerikanska utvärderingsmetodologerna Cook \& Campbell (1979) har utvecklat olika typer av validitetskrav som bör ställas på experimentella och kvasi-experimentellastudier för att resultaten ska kunna värderas som trovärdiga (dvs. om vetenskapliga påståenden är "sanna« eller "falska"). Dessa krav ligger till grund för den validitetskontroll som skett $i$ vår empiriska studie.

Cook \& Campbell skiljer mellan intern validitet (Internal Validity), extern validitet (External Validity), konstruktvaliditet (Construct Validity) och statistisk validitet (Statistical Conclusion Validity). Intern validitet avser problemet att avgöra om ett statistiskt säkerställt samband mellan två variabler är kausalt eller icke-kausalt, dvs. beror på en tredje variabel. Om man studerar effekterna av en viss intervention måste man ha mått på att insatserna enligt denna metod verkligen förekommer i en grupp och faktiskt saknas på det avsedda sättet i jämförelsegruppen. Spridning eller imitation av interventionen kan förändra den förutsatta skillnaden mellan grupperna. Extern validitet avser möjligheten till generalisering utifrån en specifik studie till antingen vissa avsedda personer, situationer och tillfällen eller generaliseringar till andra populationer. Slumpmässiga stickprov från populationen är som regel överlägsna i extern validitet eftersom de individer som ingår i undersökningsgruppen ska vara representiva. Konstruktvaliditet handlar om den teoretiska grunden för studien, t.ex. vilka teoretiska 
begrepp som man tänker sig representera ett visst orsaks- eller effektförlopp. Tydliga begreppsdefinitioner och dataanalyser med avseende på relationen mellan interventionsvariabler och utfallsvariabler ökar sannolikheten för att utfallsvariablerna verkligen berör vad de är tänkta att mäta. Statistisk validitet avser sambandet mellan orsak och effekt och hur starkt sambandet är. Sannolikheten för att dra felaktiga slutsatser om att skillnad föreligger när det faktiskt inte är fallet (typ I-fel) eller att ingen skillnad föreligger när det är fallet (typ II-fel) ökar när stickprovet är litet eller när antagandena för de statistiska testen inte är uppfyllda. I följande avsnitt beskriver jag den empiriska studie - en effektutvärdering av en handläggningsmetod för socialbidrag - som artikeln bygger på och i nästa avsnitt hur vi försökte kontrollera och åtgärda reliabilitetsoch validitetsproblematiken.

\section{Den empiriska studien: Uppsalamodellen och socialbidragstagarna, en effektutvärdering}

Uppsalamodellen uppmärksammades i början av 1990-talet som en metod i socialbidragsarbetet med syftet att hjälpa arbetslösa socialbidragstagare att så snabbt som möjligtblisjälvförsörjande. Kortarebidragstider, långsiktiga lösningar på bidragstagarnas försörjningsproblem $i$ form av arbete eller utbildning och därigenom mindre kostnader för socialbidrag är metodens intentioner. Metoden karakteriseras av omfattande krav på bidragstagarna att aktivt söka arbete som villkor för att erhålla socialbidrag, noggrann kontroll av lämnade uppgifter och betoning på den enskildes eget ansvar. I syfte att utvärdera effekterna för socialbidragstagarnaav denna handläggningsmetod, som i jämförelse med traditionella metoder ställde större krav som villkor för att erhålla bidrag, genomförde vi en kvasi-experimentell studie (Milton \& Bergström 1998). De frågor vi ville besvara i studien var om denna metodbidrog till attbidragstagarna lämnade socialbidragssystemet i större utsträckning för arbete, utbildning etc., efter kortare tid och mer stadigvarande än en alternativ handläggningsmetod. Vi ville också veta om det utbetalda bidragsbeloppet skilde sig åt. Studien omfattar 509 individer, som ansökt om ekonomiskt bistånd något av åren 1990 och 1992 och med arbetslöshet som främsta orsak. Samtliga socialbidragstagare som uppfyller dessa krav ingår i den socialbyrå som tillämpar Uppsalamodellen. Ett slumpmässigt urval har gjorts i jämförelsegruppen som omfattar bidragstagare vid en annan socialbyrå i samma stad, eftersom vi önskade ha kontroll över vissa omvärldsfaktorer av betydelse för studiens resultat, såsom att bidragsnormen är densamma för grupperna och att samma arbetsmarknad och utbildningsutbud finns att tillgå. Jämförelsegruppen har valts i syfte att vara så lik undersökningsgruppen som möjligt med hänsyn till viktiga bakgrundsfaktorer. Avsikten är att resultaten ska kunna knytas till de studerade metoderna och inte bero på andra faktorer. Vi har främst använt uppgifter ur de sociala akterna som upprättats vid socialbyråerna, kompletterat med information $i$ ett SCB-register (Årsys). Materialet har bearbetats med hjälp av olika statistiska metoder. En jämförelse mellan de två socialbidragsgrupperna (Tabell 1) visar att de skil- 
Tabell 1

Enjämförelse mellan socialbidragstagarna vid de två socialtjänstkontoren. De kategoriska variablerna anges i procent och för de kontinuerliga anges medelvärdet. Källa: Milton \& Bergström 1998.

\begin{tabular}{|c|c|c|c|}
\hline $\begin{array}{l}\text { Bakgrundsfaktorer } \\
\text { Kategoriska variabler: }\end{array}$ & $\begin{array}{c}\text { ppsalamodellen } \\
\%\end{array}$ & $\begin{array}{c}\text { Gottsunda } \\
\%\end{array}$ & P-värde \\
\hline $\begin{array}{l}\text { Kategoriska variabler: } \\
\text { Kön (kvinnor) }\end{array}$ & $\begin{array}{r}\% \\
51\end{array}$ & $\begin{array}{l}10 \\
46\end{array}$ & 0.27 \\
\hline Namn (utländskt) & 68 & 43 & $<0.001$ \\
\hline Civilstånd (gift,sambo) & 28 & 17 & 0.002 \\
\hline \multicolumn{4}{|l|}{ Bostad: } \\
\hline hyresrätt & 73 & 70 & \\
\hline bostadsrätt,villa & 4 & 4 & 0.80 \\
\hline Sjuk & 21 & 14 & 0.05 \\
\hline \multicolumn{4}{|l|}{ Utbildning: } \\
\hline grundskola & 40 & 41 & \\
\hline gymnasium & 45 & 48 & 0.32 \\
\hline högsk/universitet & 10 & 8 & \\
\hline Arbetserfarenhet i Sverige & 61 & 81 & $<0.001$ \\
\hline \multicolumn{4}{|l|}{ Sysselsättning före socialbidrag: } \\
\hline arbete & 46 & 44 & \\
\hline utbildning & 28 & 28 & 0.79 \\
\hline annat & 26 & 28 & \\
\hline Tidigare socialbidrag & 65 & 65 & 0.87 \\
\hline Ansökan 1992 & 77 & 60 & $<0.001$ \\
\hline Invandrare & 65 & 43 & $<0.001$ \\
\hline Afrika & 12 & 6 & $<0.001$ \\
\hline Asien & 39 & 23 & \\
\hline Övriga & 14 & 14 & \\
\hline \multicolumn{4}{|l|}{ Tid i Sverige: } \\
\hline I åri Sverige & 26 & 5 & $<0.001$ \\
\hline 2-5 år & 20 & 21 & \\
\hline$\geq 6 \mathrm{a} r$ & 17 & 14 & \\
\hline \multicolumn{4}{|l|}{ Kontinuerliga variabler: } \\
\hline Ålder & 30,8 & 29,4 & 0.08 \\
\hline Barn & 1.03 & 0,79 & 0.03 \\
\hline Antal tidigare socialbidragsansökninge & ngar $\quad 1,4$ & 1,42 & 0.99 \\
\hline $\begin{array}{l}\text { Tidigare antal månader } \\
\text { med socialbidrag }\end{array}$ & 13,5 & 10,6 & 0.10 \\
\hline
\end{tabular}

jer sig åt i flera avseenden, bland annat har bidragstagarna i jämförelsegruppen oftare erfarenhet av svensk arbetsmarknad, mer sällan invandrarbakgrund och har varit bosatta längre tid i Sverige än bidragstagarna i Uppsalamodellen. Det är svårt att veta orsakerna till dessa skillnader, möjligen kan de spegla skillnader i arbetsmetoder på så sätt att socialsekreterarnas bedömningar i vad mån en bidragssökande är "arbetsför" och i vad mån denne är berättigad till bidrag varit olika vid de två byråerna. De statis- 
tiska metoder vi använt vid bearbetningen av materialet kompenserar så långt möjligt för skillnaderna.

Om vi beaktar samtliga orsaker till att socialbidragstagarna lämnar bidragstagandet visar studien att socialbidragstagarna i Uppsalamodellen inte uppbär bidrag under kortare tid eller att de har större chanser att få reguljärt arbete, AMS-arbete eller utbildning (Tabell 2). För båda grupperna gäller att ansökningsåret har stor betydelse och avspeglar den dramatiska förändringen på arbetsmarknaden mellan åren 1990 och 1992. Chansen för socialbidragtagarna att bli självförsörjande genom reguljärt arbete år 1992 var bara cirka en tredjedel så stor som 1990.

De socialbidragstagare som inte uppfyller socialtjänstens krav att söka arbete eller fullgöra utbildning och därför inte beviljats fortsatt bidrag utgör en för liten grupp för att tillåta säkra slutsatser. Med reservation för detta faktum, framkommer en viss ökad risk att nekas fortsatt bidrag i Uppsalamodellen jämfört med jämförelsegruppen. Risken att inte beviljas fortsatt bidrag är större under 1992 än 1990 vilket kan betyda att kravet på motprestationer ökar under perioden.

Studien visar också att det var vanligare att bidragstagarna i Uppsalamodellen än i jämförelsegruppen återkom med begäran om socialbidrag (Tabell 3). Ett skäl kan vara att Uppsalamodellen ställde alltför höga krav på bidragstagarna att deltaga i kvalificerade aktiviteter eller fullgöra uppgifter som bidragstagarna inte var motiverade att genomföra. För samtliga bidragtagare i studien gäller att de som ansökte om och beviljades socialbidrag år 1990, återkom betyd- ligt oftare än de som ansökte om bidrag år 1992. En förklaring kan vara att de personer som trots en kärvare arbetsmarknad lyckades lämna bidragssystemet, hade särskilt goda förutsättningar att få och behålla ett arbete.

Det finns inga skillnader mellan de två jämförda socialkontoren i fråga om beviljat bidragsbelopp till de arbetslösa socialbidragstagarna. Eventuella lägre bidragskostnader i den kommundel som tillämpar Uppsalamodellen, vilket framförts i debatten men inte undersökts i denna studie, kan ha många förklaringar exempelvis att färre anses berättigade till bidrag och fler därmed får avslag på bidragsansökningen. De som anses berättigade till bidrag, tycks emellertid inte drabbas av lägre ersättningsnivåer.Sammanfattningsvis ger resultaten från denna studie, med den uppläggning vi valt och med reservation för att endast två socialbyråer ingår i studien, inte stöd för att Uppsalamodellen uppfyller de intentioner den avser bättre än jämförelsegruppen.

\section{Reliabilitets- och validitetskontrollerna vid datainsamling och analys av studiens resultat.}

Studien bygger på tillgången till ett stort material och urvalet ur det kommunala bidragsregistret omfattar därför samtliga bidragstagare - som ansökt om ekonomiskt bistånd någon gång under 1990 och 1992 med arbetslöshet som främsta orsak - vid den socialbyrå som tillämpar Uppsalamodellen och ett slumpmässigt urval vid den jämförda socialbyrån. Med detta förfarande 
Tabell 2

Multivariat Cox modell för olika orsaker att lämna socialbidragstagandet.

(Källa: Milton \& Bergström 1998)

\begin{tabular}{|c|c|c|c|c|}
\hline \multirow[b]{2}{*}{ Variabel } & \multicolumn{2}{|c|}{$\begin{array}{c}\text { Reguljärt arbete. Antal }=49 \mid \\
\text { Antal } \mathrm{i} \text { arbete }=\mid 29\end{array}$} & \multicolumn{2}{|c|}{$\begin{array}{c}\text { Samtliga orsaker. } \text { Antal }=491 \\
\text { Antal } \mathrm{i} \text { arbete } \mathrm{mm}=374\end{array}$} \\
\hline & RS & $95 \% \mathrm{CL}$ & RS & $95 \% \mathrm{CL}$ \\
\hline Kontor & 0.88 & $0.59-1.31$ & 1.03 & $0.83-1.30$ \\
\hline Arbetserfarenhet & 3.40 & $1.80-6.44$ & 1.86 & $1.37-2.50$ \\
\hline Ansökningsår & 0.33 & $0.22-0.50$ & 0.97 & $0.76-1.24$ \\
\hline \multicolumn{5}{|l|}{ Nationalitet: } \\
\hline Norden & 0.88 & $0.37-2.09$ & 0.83 & $0.47-1.46$ \\
\hline Europa & 1.02 & $0.44-2.39$ & 0.54 & $0.29-1.01$ \\
\hline Afrika & 1.03 & $0.50-2.10$ & 0.64 & $0.40-1.01$ \\
\hline Amerika & 1.41 & $0.62-3.21$ & 1.17 & $0.70-1.94$ \\
\hline Asien & 0.60 & $0.34-1.04$ & 0.89 & $0.67-1.20$ \\
\hline Okänt & 2.59 & $0.89-7.51$ & 1.58 & $0.72-3.47$ \\
\hline Civilstånd & 0.53 & $0.28-0.96$ & 0.93 & $0.68-1.26$ \\
\hline Kön & 1.09 & $0.74-1.63$ & 0.90 & $0.72-1.14$ \\
\hline \multicolumn{5}{|l|}{ Ålder: } \\
\hline $15-19$ & 0.61 & $0.21-1.82$ & 0.89 & $0.54-1.45$ \\
\hline $20-24$ & 1.00 (ref) & 1.00 (ref) & & \\
\hline $25-29$ & 1.01 & $0.62-1.64$ & 0.96 & $0.71-1.31$ \\
\hline $30-34$ & 0.57 & $0.30-1.08$ & 0.83 & $0.57-1.20$ \\
\hline $35-39$ & 0.61 & $0.27-1.34$ & 0.70 & $0.43-1.13$ \\
\hline $40-$ & 0.31 & $0.16-0.63$ & 0.81 & $0.55-1.21$ \\
\hline \multicolumn{5}{|l|}{ Antal barn: } \\
\hline 1 & 0.66 & $0.41-1.07$ & 0.77 & $0.58-1.02$ \\
\hline 2 & 0.80 & $0.40-1.58$ & 0.73 & $0.50-1.06$ \\
\hline$\geq 3$ & 0.59 & $0.25-1.38$ & 0.87 & $0.53-1.42$ \\
\hline \multicolumn{5}{|l|}{ Bostad: } \\
\hline Hyres & 1.42 & $0.88-2.30$ & 1.03 & $0.78-1.37$ \\
\hline Br,villa & 1.28 & $0.42-3.92$ & 1.75 & $\mid .02-3.01$ \\
\hline Sjuk & 0.47 & $0.26-0.83$ & 0.79 & $0.59-1.06$ \\
\hline \multicolumn{5}{|l|}{ Utbildning: } \\
\hline$<$ Grundskola & 0.29 & $0.04-2.17$ & 0.56 & $0.29-1.09$ \\
\hline Grundskola & 1.00 (ref) & 1.00 (ref) & & \\
\hline Gymnasium & 1.62 & $1.04-2.52$ & 1.49 & $1.15-1.92$ \\
\hline Högsk/universitet & 1.93 & $0.86-4.33$ & 1.31 & $0.81-2.12$ \\
\hline Uppgift saknas & 3.71 & $1.71-8.06$ & 1.96 & $1.18-3.24$ \\
\hline Tidigare socialbidrag & 0.983 & $0.971-0.990$ & 0.988 & $0.982-0.995$ \\
\hline
\end{tabular}

\section{Reguljärt arbete. Antal $=49$ | Antal $i$ arbete $=129$ \\ $3.40 \quad 1.80-6.44$ \\ $0.33 \quad 0.22-0.50$}

0.88

$0.37-2.09$

$0.44-2.39$

$0.50-2.10$

$0.62-3.21$

0.53

0.61

$1.00(\mathrm{ref})$

1.00 (ref)

$0.27-1.34$

$0.16-0.63$

0.66

$0.41-1.07$

$0.40-1.58$

$0.88-2.30$

$0.42-3.92$

$0.26-0.83$

$\mathrm{RS}=$ relativ sannolikhet. $\mathrm{CL}=$ konfidensintervall. Ref=referensgrupp
$0.89 \quad 0.54-1.45$

$0.96 \quad 0.7|-| .3 \mid$

$0.83 \quad 0.57-1.20$

$0.70 \quad 0.43-1.13$

$0.55-1.21$

$0.77 \quad 0.58-1.02$

$0.73 \quad 0.50-1.06$

$1.03-0.78-1.37$

$1.75 \quad \mid .02-3.01$

$0.79 \quad 0.59-1.06$

$0.56 \quad 0.29-1.09$

$1.49 \quad 1.15-1.92$

$1.31 \quad 0.81-2.12$

$0.988 \quad 0.982-0.995$ 
Tabell 3

Multivarat Cox modell för Återkommande bidragsansökan. Antal observationer:372, antal nya ansökningar: 162. (Källa:Milton \& Bergström 1998).

\begin{tabular}{|c|c|c|}
\hline Variabel & RS & $95 \% \mathrm{CL}$ \\
\hline \multicolumn{3}{|l|}{ Orsak: } \\
\hline arbete & 1.27 & $0.74-2.19$ \\
\hline AMS & 0.69 & $0.40-1.21$ \\
\hline utb & 1.15 & $0.70-1.87$ \\
\hline övrigt & 1.00 & $0.62-1.62$ \\
\hline \multicolumn{3}{|l|}{ Kontor } \\
\hline Gottsunda & 1.60 & $1.13-2.25$ \\
\hline Gla Uppsala & 0.99 & $0.61-1.59$ \\
\hline Ansökn.år & 0.58 & $0.40-0.88$ \\
\hline \multicolumn{3}{|l|}{ Nationalitet } \\
\hline Norden & 0.53 & $0.16-1.73$ \\
\hline Europa & 0.35 & $0.10-1.20$ \\
\hline Afrika & 0.84 & $0.42-1.65$ \\
\hline Amerika & 1.14 & $0.56-2.31$ \\
\hline Asien & 0.88 & $0.55-1.41$ \\
\hline Okänt & 0.22 & $0.03-1.65$ \\
\hline Civilstånd & 0.96 & $0.61-1.53$ \\
\hline Kön & 0.82 & $0.56-1.18$ \\
\hline \multicolumn{3}{|l|}{ Ålder } \\
\hline$\leq 19$ & 0.49 & $0.20-1.18$ \\
\hline$\overline{25}-29$ & 0.73 & $0.46-1.16$ \\
\hline $30-34$ & 0.49 & $0.27-0.88$ \\
\hline $35-39$ & 0.85 & $0.44-1.64$ \\
\hline $40-$ & 0.70 & $0.40-1.25$ \\
\hline \multicolumn{3}{|l|}{ Antal barn } \\
\hline I & 1.11 & $0.71-1.73$ \\
\hline 2 & 0.96 & $0.54-1.73$ \\
\hline$\geq 3$ & 1.50 & $0.74-3.04$ \\
\hline \multicolumn{3}{|l|}{ Bostad } \\
\hline hyres & 0.81 & $0.52-1.25$ \\
\hline Br/villa & 0.94 & $0.40-2.20$ \\
\hline Sjuk & 1.33 & $0.82-2.07$ \\
\hline \multicolumn{3}{|l|}{ Utbildning } \\
\hline <grundskola & 0.82 & $0.23-2.93$ \\
\hline gymnasium & 1.02 & $0.69-1.50$ \\
\hline högsk/univ & 1.10 & $0.55-2.20$ \\
\hline ej uppgift & 0.57 & $0.26-1.28$ \\
\hline Mån före soc.b & 1.009 & $0.999-1.019$ \\
\hline
\end{tabular}

\section{Variabel}

arbete

AMS

utb

\section{Gottsunda}

Ansökn.år

ationalite

Norden

Europa

Afrika

Amerika

1.14

0.22

0.96

Kön

Alder

$\leq 19$

30-34

0.73

0.49

0.85

$0.44-1.64$

35-3

ntal barn

$\geq 3$

hyres

Br/villa

tbildning

$<$ grundskola

högsk/univ

ej uppgift

$\mathrm{RS}=$ relativ sannolikhet. $\mathrm{CL}=$ konfidensintervall. kan vi möta några av hoten mot reliabiliteten och den externa validiteten. Det slumpmässiga urvalet möjliggör bland annat att resultaten är generaliserbara. För studiens syfte krävdes också att jämförelsegruppen verkligen får en annan typ av handläggning. Därför är det väsentligt att utröna på vilket sätt de två arbetssätten skiljer sig åt och om de överensstämmer på några områden. Genom intervjuer med socialcheferna samt gruppledare och socialsekreterare vid de två socialbyråerna (totalt sex personer), vilka arbetade med arbetslösa socialbidragssökande under destuderadeåren, har vi därför försökt att så långt möjligt - med reservation för minnesfel, glömska och kanske tillrättalagd information - få en rättvis bild av arbetsmetoderna. Vi har också gått igenom interna dokument och verksamhetsrapporter. Båda socialkontoren hade arbetslinjen som grund men de arbetade på delvis olika sätt för att uppnå målen. De skillnader vi fann mellan arbetsmetoderna är främst att den studerade metoden har mer rigorös och rutinmässig kontroll inför bedömning av vilka som är berättigade till socialbidrag, använder strukturerade intervjuer vid bedömningen av klientens situation och problem, ger tätare besökstider samt har hårdare krav på klientens egen aktivitet att söka arbete eller fullgöra utbildning som villkor att erhålla socialbidrag. Samtliga socialsekreterare i den studerade socialbyrån hade kontakt med arbetsförmedlingen, vid den jämförda socialbyrån ansvarade en särskild socialsekreterare för samarbetet och handläggningen av socialbidraget sköttes i övrigt av klienternas respektive handläggare. Ytterligare en betydelsefull skillnad är att förslag till insatser och motiv till beslut föredras 
och diskuteras i hela arbetsgruppen i den studerade metoden. Dessutom har socialkontoren olika mängd resurser, den studerade metoden hade betydligt färre ärenden per handläggare och kunde avsätta mer tid för varje bidragssökande. Möjligheten att vissa delar av den studerade metoden övertagits ("spillover") av socialbidragshandläggarna i jämförelsegruppen finns naturligtvis och svårigheter att $\mathrm{i}$ efterhand bedöma vad som verkligen görs och vad som är retorik är ofrånkomliga. I socialt arbete är insatserna eller interventionerna ofta svåra att definiera och systematisera eftersom de många gånger är komplexa och kan pågå under lång tid (Jfr Lawlor \& Raube 1995).

Efter detta inledande arbete kunde vi precisera studiens syfte och definiera de beroende och oberoende variablerna i mätbara termer, vilka ytterligare preciserades i den pilotstudie som låg till grund för denstörre studien. Pilotstudien omfattande ett 20-tal sociala akter om socialbidragstagarna, med avsikt att studera tillgången till uppgifter och datakvaliteten för individdata, interventionsdata och utfallsdata. Vi utarbetade ett kodningsinstrument, dvs. en beskrivande variabellista för att systematisera informationen i akterna och definiera variablerna. Pilotstudien visade att flertalet av de uppgifter vi sökte hade dokumenterats i akterna, men att vissa för studien betydelsefulla uppgifter saknades, främst uppgifter om socialbidragstagarnas utbildning, arbetslivserfarenheter, deras sysselsättning före bidragsansökan samt deras nationalitet och vistelsetid i Sverige (aktmaterialet var likartat vid de båda kontoren med avseende på uppgifter och systematik). Eftersom samtliga dessa faktorer $i$ andra studier visat ett starkt samband med socialbidragstagande (Bergmark 1991, Halleröd 1991, Salonen 1994) såg vi det som nödvändigt för syftet med vår studie att få tillgång till dessa uppgifter. Data från aktstudien har därför, efter tillstånd från datainspektionen, samkörts med ett av Statistiska centralbyråns register om den årliga sysselsättningen (Årsys) i syfte att få kompletterande information. Årsys omfattar samtliga folkbokförda personer i Sverige per den 31 december varje år och har konstruerats från flera olika register. Årsys-data användes antingen för att uppgifter helt saknades i akterna eller för att dessa data bedömdes vara mer precisa än uppgifterna i akterna. Studiens datakvalitet har på så sätt kontrollerats med hjälp av ett nationellt register; när osäkerhet rått om uppgifternas kvalitet eller uppgifter helt saknats i akterna har Årsys registeruppifter använts. I syfte att ytterligare öka tillförlitligheten $i$ våra data har ett enhetligt tolknings- och kodningsarbete eftersträvats genom att samma person samlat in uppgifterna.

Informationen söktes främst i de sociala akterna och rörde individkarakteristika, den sociala interventionens karaktär och utfall för bidragstagarna. Uppgifter om bidragstagarnas ålder, kön, nationalitet, familjesammansättning och antal barn, typ av bostad, sjukdom, tidigare socialbidragsperioder, utbildning, sysselsättning och arbetslivserfarenhet före socialbidragsansökan fanns i de flesta akter. Några uppgifter saknades eller var oprecisa, av i studien sammanlagt ingående 509 fall saknades uppgift om utbildning för 106 individer, arbetslivserfarenhet för 15 , nationalitet för 10 och om vistelsetid i Sverige för samtliga 509 indivi- 
der.Sådana data kompletterades med registret. Mer detaljerade uppgifter, t.ex. om heloch deltidsarbete, saknades helt och fick uteslutas i studien. De uppgifter vi sökte om interventionen, omfattade tidpunkt för första kontakt med socialtjänsten, frekvens för samtal eller andra överenskommelser, frekvensförbeslut ombifall tillsocialbidrag, bidragstidens längd och utbetalt belopp. Dessa uppgifter fanns i samtliga akter. Uppgifterna om samtalsfrekvens bekräftade den skillnad mellan arbetsmetoder som framkommit $i$ intervjuerna, nämligen att socialsekreterarna som tillämpade Uppsalamodellen träffade sina klienter något oftare under bidragstiden. I akterna fanns dock relativt få mätbara indikatorer för den sociala interventionen. Eftersom vi ville undersöka effekterna av ett visst interventionsprogram är detta naturligtvis en brist. Intervjuer med ett antal nyckelpersoner var ett sätt att kontrollera interventionsvariablerna och undersöka i vilken utsträckning det fanns likheter och skillnader mellan de jämförda arbetsmetoderna och mellan det ideala och det faktiska arbetet i undersökningsgruppen. Trots dessa kontroller finns naturligtvis osäkerhet om hur noggrannt socialsekreterarna dokumenterat interventioner och utfall. Vissa för studien intressanta uppgifter saknadesocksåheltiakterna, exempelvis vadolika överenskommelser med klienten innebar och hur samarbetet mellan socialtjänsten och arbetsförmedling fortlöpte och vad det omfattade.

Utfallsvariablerna som vi fann i akterna omfattade tidpunkt för avslutning av ärendet, olika typer av försörjning och återkommande ansökan om socialbidrag. Uppgifter om orsaken till att lämna bidragssystemet för annan försörjning saknades för 14 individer. För ytterligare 77 vet vi att de har flyttat från kommunen, men inte om de lämnat bidragssystemet. Dekan ha flyttat till någon annan kommun och där beviljats socialbidrag eller flyttat till annan kommun för att arbeta, fullfölja utbildning mm. Endast för 14 individer, som tidigare nämnts, saknades uppgifter om vad som hänt sedan de lämnat socialbidragstagandet och vi har därför uppgifter om nästan samtliga klienter i studien när det gäller vilka som återkommer med bidragsansökningar och efter hur lång tid. När det gäller utfallsvariablerna finns osäkerhet om den grupp som angetts som "flyttat" som orsak till att de lämnat bidragstagandet. För den gruppen känner vi egentligen inte till om de lämnat bidragssystemet - de kan ha flyttat till någon annan kommun och där beviljats socialbidrag - eller flyttat till annan kommun för att arbeta, fullfölja utbildning osv.

Eftersom det interna bortfallet, dvs. utelämnade uppgifter i vissa variabler, är av begränsad omfattning i studiens datamaterial baseras de statistiska analyserna på ett närmast komplett material. Vi har använt enkel linjär regressionsanalys (OLS) i syfte att studera om det finns några skillnader mellan de två handläggningsmodellerna med avseende på det beviljade, utbetalda socialbidragets storlek. Sambandet mellan utbetalt socialbidragsbelopp och de förklarande variablerna har analyserats. För att besvara de övriga frågorna har andra analysmetoder, vilka utvecklats särskilt för att bearbeta tidsberoende företeelser i samband med "varaktighet", använts. I stället för att jämföra den tid socialbidragstagarna uppbär bidrag, kan man jämföra sannolikheten per 
tidsenhet att socialbidragstagarna lämnar bidragstagandet. Om tiden med socialbidrag är mycket lång bör sannolikheten att lämna bidragstagandet vara liten. Oberoende av vilken av variablerna som studeras uppstår problem, eftersom vissa individer fortfarande uppbär socialbidrag eller har flyttat från orten, närstudiens observationsperiod avslutas. I dessa fall saknar vi kunskap om den exakta tiden när individerna lämnar socialbidragstagandet, det föreligger s.k. högercensurerade observationer, och vi vet endast att observationsvärdet är större än det senast registrerade värdet. Vanliga analysmetoder, såsom t-test, chi-två-test och vanlig regressionsanalys, kan därför inte användas för att jämföra grupperna. Särskilda metoder har emellertid utvecklats för denna situation, som ofta uppstår när datamaterialet är av varaktighetskaraktär, s.k. intensitetsregression. Vi har använt en sådan, ofta använd modell nämligen $\mathrm{Cox}$ proportional hazards $(\mathrm{PH})$ modell. Materialet har bearbetats i univariata och multivariata analyser, i syfte att undersöka dels enskilda variablers effekter, dels samvariationen mellan flera variabler, som påverkar den beroende variabeln i respektive frågeställning. För att kontrollera att resultaten är robusta har vi analyserat materialet med hjälp även av andra statistiska metoder för datamaterial av varaktighetskaraktär. Resultaten av dessa analyser visar att våra resultat är stabila oberoende av vilken av de statistiska metoderna som används (Milton \& Bergström, kommande artikel). Sammanfattningsvis har vi varit uppmärksamma på de reliabilitets- och validitetskrav man bör ställa på studier som vår och försökt att åtgärda validitetsproblemen enligt Cook \&
Campbell och i någon liten mån lyckats säkerställa studiens resultat (Tabell 4).

\section{Sammanfattning och diskussion}

Intresset för att följa upp och utvärdera det sociala arbetets metoder och effekter har blivit alltmer uttalat under senare år. Förutom etiska hänsyn och metodologiska problem har ofta bristen på tillräckligt stora datamaterial av god kvalitet angetts som ett hinder att genomföra effektutvärderingar inom socialt arbete. I det dagliga arbetet dokumenterar socialarbetarna emellertiden mängd uppgifter om sina klienter i de sociala akterna. Det finns både för-och nackdelar i att använda sociala akter i utvärderingar, och många gånger kan studier grundade på primärdata vara att föredra. I en utvärdering av en metod inom socialbidragsarbetet som ställde större krav på bidragstagarna som villkor att erhålla bidrag jämfört med andra metoder, använde vi de sociala akterna som huvudsaklig informationskälla. I syfte att få en så tillförlitlig och trovärdig studie som möjligt prövade vi uppgifternas och resultatens reliabilitet och validitet på olika sätt och byggde därvid främst på Cook \& Campbell's metodologi för validitetskontroll. Tvivelaktig datakvalitet kan leda till felaktiga slutsatser ochkonsekvenser för den studerade verksamheten, vilket vi naturligvis önskade undvika.

Studien bygger på ett stort material, vi har tillämpat ett slumpmässigt urvalsförfarande och jämför den studerade gruppen med noga utvald jämförelsegrupp. Uppgifterna i akterna har definierats som mätbara variabler och dokumenterats av en person 
Tabell 4

Sammanfattning av studiens validitetskontroll i enlighet med Cook \& Campbells metodologi.

\begin{tabular}{|c|c|c|c|}
\hline Validitetskrav & Syfte & Metod/Åtgärd & Resultat \\
\hline Intern validitet & $\begin{array}{l}\text { Bevisvärdet för kausala } \\
\text { och icke-kausala sam- } \\
\text { band, inverkan av mel- } \\
\text { lanliggande variabler }\end{array}$ & $\begin{array}{l}\text { Intervjuer komplette- } \\
\text { rar aktdata }\end{array}$ & $\begin{array}{l}\text { Viss osäkerhet om skill- } \\
\text { naderna mellan de två } \\
\text { studerade metoderna }\end{array}$ \\
\hline Extern validitet & Generaliserbarhet & $\begin{array}{l}\text { Stort material, slump- } \\
\text { mässigt urval }\end{array}$ & $\begin{array}{l}\text { Studiens resultat är } \\
\text { generaliserbara }\end{array}$ \\
\hline Konstruktvaliditet & $\begin{array}{l}\text { Teoretisk grund och } \\
\text { begreppsdefinitioner } \\
\text { med avseende på rela- } \\
\text { tionen mellan inter- } \\
\text { ventions- och utfallsva- } \\
\text { riabler }\end{array}$ & $\begin{array}{l}\text { Teoretiska begrepps- } \\
\text { definitioner av bero- } \\
\text { ende och oberoende } \\
\text { variabler.Variabellista. }\end{array}$ & $\begin{array}{l}\text { Tydliga definitioner. } \\
\text { Mätbara mål (=model- } \\
\text { lens intentioner) }\end{array}$ \\
\hline Statistisk validitet & $\begin{array}{l}\text { Styrkan av sambandet } \\
\text { mellan intervention/ } \\
\text { orsak och utfall/effekt }\end{array}$ & $\begin{array}{l}\text { Nästan komplett } \\
\text { material (akter kom- } \\
\text { pletterade med natio- } \\
\text { nellt register). Multiva- } \\
\text { riatanalyser. Flera olika } \\
\text { statistiska modeller har } \\
\text { använts }\end{array}$ & $\begin{array}{l}\text { Viss osäkerhet om hur } \\
\text { jämförbara de två stu- } \\
\text { derade grupperna är } \\
\text { (ett problem som åter- } \\
\text { kommer i denna typ av } \\
\text { studier) }\end{array}$ \\
\hline
\end{tabular}

för att uppnå enhetlighet i tolknings- och kodningsarbetet. Genom kompletterande registerdata och intervjuer med personal har datakvaliteten kontrollerats och i någon mån säkrats. Vi genomförde därför intervjuer med ett antal nyckelpersoner i syfte att kontrollera interventionsvariablerna och undersöka i vilken utsträckning det fanns likheter och skillnader mellan de jämförda arbetsmetoderna och mellan det ideala och det faktiska arbetet i undersökningsgruppen. Helst ska den jämförda metoden vara helt annorlunda och gärna "traditionell» i den meningen att den är representativ för allt övrigt socialbidragsarbete i landet.
Det råder en viss osäkerhet om skillnaderna mellan metoderna. Troligen ställer man även vid jämförelsekontoret större krav på bidragstagarna att aktivt söka självförsörjning än många andra socialbyråer i landet. I de statistiska bearbetningarna har sambandet mellan orsak och effekt och hur starkt sambandet är testats på olika sätt. Med hjälp av olika statistiska modeller har resultaten kontrollerats och funnits vara robusta. Den osäkerhet som ändå fortfarande finns om gruppernas jämförbarhet leder till att resultaten bör tolkas med viss försiktighet.

Erfarenheterna från den utvärdering av socialbidragsarbetets effekter som beskri- 
vits, grundad på främst information ur sociala akter, visar att uppgifter i akterna kan användas vid effektutvärderingar. Det krävs emellertid att man är uppmärksam på materialets begränsningar och reliabilitets- och validitetsproblematiken och vidtar sådana åtgärder som så långt möjligt - troligen är det eftersträvansvärt men knappast möjligt att helt lyckas - reducerar dessa begränsningar. En förutsättning är att relevanta uppgifter om socialbidragstagarna, arbetsmetoder och resultat dokumenteras systematiskt och strukturerat, något som kan variera vid olika socialkontor. Det kan innebära särskilda svårigheter att avgränsa och definiera insatsernas beståndsdelar och utfallet, vilket krävs för att utvärdera sociala insatsers effekter för människor. Det ställer troligen särskilda krav på utvärderingsforsk- ning inom socialtjänstens område, där den sociala praktiken består av ett komplex av processer i ständig förändring och där interventioner och utfall sällan är särskilt tydligt definierade.

Den alltmer utvecklade datoriseringen inom socialbidragsarbetet underlättar troligen en mer enhetlig, systematisk dokumentation av grundläggande uppgifter om klienternas individuella egenskaper, interventionernas karaktär och utfallet för klienterna. Relevanta och jämförbara data mellan socialbyråerna ger ökade möjligheter till uppföljning och, åtminstone på sikt, utvärdering av socialbidragsarbetet och dess effekter. Det bör kunna leda till att arbetet i högre grad än idag har sin grund $i$ vetenskapligt belagd kunskap.

\section{Litteratur}

Ben Shahar I, Auslander G \& Cohen H(1995) Utilizing data to improve practice in hospital social work: A case study. Social Work in Health Care, 20:99-111.

Bernler G \& Johnsson L (1993) Den sociala journalen I: En studie i akter - deras struktur och funktion. Rapport 1993:7, Göteborgs universitet, Göteborg.

Bergmark Å (1991): Socialbidrag och försörjning. Diss, Socialhögskolan, Stockholms universitet.

Boruch R (1997) Randomized experiments for planning and evaluation. Thousands Oaks, CA, Sage.

Buhr P, Ludwig M \& Priester T (1990) Die Bremer $10 \%$ stichprobe von sozialhilfeakten. Konstruktion und Auswertungsperspektiven. Arbeitspapier nr 1/90. Zentrum für Sozialpolitik. Universität Bremen.

Campbell D T, Stanley J C (1966) Experimental and quasi-experiments designs for research. Chicago, Ill, Rand McNally.
Cheetham J, Fuller R, Mclvor G \& Petch A (1992): Evaluating social work effectiveness. Buckingham/Philadelphia: Open University Press.

Cook T D \& Campbell D T (1979) Quasi-experimentation: Design and analyses for field settings. Chicago, IL: Rand McNally.

Edholm H \& Jacobsson L (1999) Bättre koll på socialbidraget - om förutsättningar för att följa socialbidragsutvecklingen med ADB-stöd. Stencil, Socialstyrelsen.

Epstein I, Zilberfein F \& Snyder S (1997) „Using available information in practice-based outcomes research: A case study of psycho-social risk factors and liver transplant outcomes."I Mullen E \& Magnabosco J (ed.) Outcomes in the human services: Cross-cutting issues and methods. Washingtin DC, NASW Press.

Fuller R \& Petch A (1989) Organisation and Outcomes: Services tothe Elderly.Social Work Research Centre, University of Stirling. 
Halleröd B (1991) Den svenska fattigdomen. Arkiv avhandlingsserie 36 , Lund.

Kagle Doner J (1983) "The contemporary social work record."Social work 28:149-153.

LawlorE\& RaubeK(1995)»Social Interventionsand Outcomes in Medical Effectiveness Research." Social Service Review 69, 3:383-404.

Mclvor G (1989) An Evaluative Study of Community Service by Offenders in Scotland. Social Work Research Centre, University of Stirling.

Milton P \& Bergström R (1998) Uppsala-modellen och socialbidragstagarna. En effekt-utvärdering. CUS-skrift 1998:1.
Milton P \& Bergström R (1999) An Evaluation of Two Regimes for Social Assistance (in prep).

Palfrey C, Phillips C \& Thomas P (1994): Evaluating Health and Social Care. Macmillan Press LTD, London.

Rossi P, Freeman H (1993) Evaluation. Newbury Park, CA, Sage.

Salonen T (1994) Välfärdens marginaler. Publica, Stockholm.

Weiss C (1972) Evaluation Research. Methods of Assessing Program Effectiveness. Prentice-Hall Inc, Englewood Cliffs, New Jersey.

\section{Summary \\ How to know about intervention outcomes? Using social work records in an evaluation of two regimes for social assistance.}

This articleasserts that information in social work records can be converted into valuable retrospective data bases for quasi-experimental outcome studies if the researcher control for the many threats to reliability and validity. The process, presented and recommended by Cook and Campbell, and its results for maximizing reliability and validity are described, using an evaluation mainly based on information in social work records as an example. 